European Journal of Pharmacology, 31 (1975) 166-175

(c) North-Holland Publishing Company, Amsterdam - Printed in The Netherlands

\title{
EFFECTS OF ALDRIN-TRANSDIOL ON NEUROMUSCULAR FACILITATION AND DEPRESSION
}

\author{
LOUIS M.A. AKKERMANS, JOEP VAN DEN BERCKEN and JOHAN M. VAN DER ZALM \\ Institute of Veterinary Pharmacology and Toxicology, \\ University of Utrecht, Biltstraat 172, Utrecht, The Netherlands
}

Received 10 July 1974, revised MS received 23 October and 4 December 1974, accepted 11 December 1974

L.M.A. AKKERMANS, J. VAN DEN BERCKEN and J.M. VAN DER ZALM, Effects of aldrin-transdiol on neuromuscular facilitation and depression, European J. Pharmacol. 31 (1975) 166-175.

The effects of aldrin-transdiol, one of the active metabolites of the insecticide dieldrin, on evoked transmitter release, neuromuscular facilitation and neuromuscular depression have been studied in frog sartorius nerve-muscle preparations. Conventional techniques of intracellular recordings were used. Aldrin-transdiol caused a marked increase in end-plate potential amplitude under conditions of low quantal content, i.e., in $\mathbf{M g}^{2+}-b_{l o c k e d}$ junctions. The increase in end-plate potential amplitude was less pronounced in curarized junctions, in which the transmitter release was not impaired. Concomitant with the increase in end-plate potential size there was a marked enhancement of facilitation during short trains of stimuli applied to the motor nerve. The decay of facilitation was, however, not seriously affected by aldrin-transdiol. These effects may be explained in terms of the known 'calcium hypothesis' by assuming that aldrin-transdiol increases the amount of calcium which enters the nerve terminal during the nerve impulse.

The increase in end-plate potential amplitude and in facilitation by aldrin-transdiol was transient. At later stages of poisoning, end-plate potential and facilitation decreased below control level and neuromuscular depression was significantly enhanced. This latter effect may be the result of a direct inhibitory effect of aldrin-transdiol on transmitter mobilization. As far as the fall in end-plate potential amplitude is concerned the known suppressive action of aldrin-transdiol on the chemical sensitivity of the postsynaptic membrane and on the nerve action potential probably plays a part as well. Finally, neuromuscular transmission was completely blocked by aldrintransdiol.

Aldrin-transdiol

Dieldrin

Neuromuscular junction

End-plate potentials
Neuromuscular facilitation

Neuromuscular depression

\section{Introduction}

There is now substantial evidence that the insecticide dieldrin is first converted to aldrin-transdiol and possibly other metabolites before it can exert its neurotoxic action. This was first suggested by Wang et al. (1971) who found that aldrin-transdiol was more potent and rapid than dieldrin itself and several other dieldrin derivatives in causing synaptic afterdischarges and in increasing spontaneous activity in the central nervous system of the cockroach. Further investigations have revealed that aldrin-transdiol causes a blockade of the action potential, mainly by suppressing the sodium current, and a depolarization of the membrane in squid giant axons. By contrast, dieldrin itself does not have any significant effect on nerve membranes even in higher concentrations and after longer exposure (Giannotti et al., 1956; Ryan and Shankland, 1971; Narahashi, 1971; Van den Bercken, 1972; Van den Bercken and Narahashi, 1974).

Akkermans et al. $(1973,1974)$ have recently demonstrated that aldrin-transdiol has a powerful action on synaptic transmission in the frog motor end-plate, while dieldrin itself and two other metabolites again remained 
without any effect. At first aldrin-transdiol causes a marked stimulation of both spontaneous and evoked transmitter release, followed later by a blockade of transmission. This latter effect could be partly explained by a suppression of the chemical sensitivity of the postsynaptic membrane as measured by iontophoretically applied acetylcholine. It was also shown that aldrin-transdiol inhibits the increase in spontaneous transmitter release induced by high external potassium concentration. This led to the hypothesis that aldrintransdiol directly interferes with the mobilization of transmitter in the motor nerve terminal.

Since the cyclodiene insecticide aldrin is rapidly converted to dieldrin, both in insects (Brooks, 1960; Giannotti et al., 1956), and in mammals (Bann et al., 1956), both insecticides probably have a common metabolic fate and the effects of aldrin-transdiol will therefore also hold good for aldrin. Aldrin-transdiol has been identified as a metabolite of dieldrin and aldrin in mammals and insects (Korte and Arent, 1965; Matthews and Matsumura, 1969; Feil et al., 1970; Baldwin et al., 1972; Tomlin, 1968; Matsumura, 1972).

The purpose of the present study was to further analyse the effects of aldrin-transdiol on synaptic transmitter release. This was done by investigating the effects of aldrin-transdiol on neuromuscular facilitation (Katz and Mile$\mathrm{di}, 1968,1970$ ) and depression (Otsuka et al., 1962; Thies, 1965).

\section{Materials and methods}

\subsection{Materials}

Experiments were performed on sartorius nerve-muscle preparations isolated from prechilled, decapitated frogs (Rana esculenta and Rana temporaria). The muscle was mounted in an $8 \mathrm{ml}$ bath and stretched to 1.2 times its maximal length in situ. The bath was continuously perfused with Ringer solution at a rate of $6 \mathrm{ml} / \mathrm{min}$ (containing in $\mathrm{mM}$ : $\mathrm{NaCl} 115$,
$\mathrm{KCl} 2.5, \mathrm{NaH}_{2} \mathrm{PO}_{4} \quad 0.85, \mathrm{Na}_{2} \mathrm{HPO}_{4} 2.15$ and $\mathrm{CaCl}_{2}$ 2.0; at $\mathrm{pH} 7.1-7.3$ ) and after about $5 \mathrm{~min}, 95 \%$ of the bathing solution was changed. Aldrin-transdiol (99\%, 1,2,3,4,10,10hexachloro - 6,7 -trans -dihydroxy -1,4-endo-5,8exo-dimethano- $1,4,4 \mathrm{a}, 5,6,7,8,8 \mathrm{a}$-octahydronaphthalene) was added to the Ringer solution with ethanol used as solvent. The final concentration of ethanol, which was less than $0.025 \%$, was found to have no effects in control experiments. The bath temperature was kept at $18 \pm 0.2^{\circ} \mathrm{C}$ with the aid of a thermoelectric device.

\subsection{End-plate potential}

End-plate potentials (e.p.p.'s) were recorded by means of conventional intracellular capillary microelectrodes filled with $3 \mathrm{M} \mathrm{KCl}$ and having resistances of between 8 and $25 \mathrm{M} \Omega$. The motor nerve was stimulated by way of a suction electrode with rectangular pulses of $0.1 \mathrm{msec}$ in duration delivered through a photoelectric isolation unit. E.p.p.'s were recorded on magnetic tape for further analysis. In order to block neuromuscular transmission and to prevent transmitter depletion the $\mathrm{CaCl}_{2}$ concentration was lowered to $0.3-0.5$ $\mathrm{mM}$ and $3-5 \mathrm{mM} \mathrm{MgCl} \mathrm{Mas}_{2}$ wadded. Osmolarity was maintained by isotonic substitution for $\mathrm{NaCl}$. In other experiments $2-6 \times 10^{-6}$ $\mathrm{g} / \mathrm{ml}$ d-tubocurarine chloride (Nourypharma) was used to enable records to be made of e.p.p.'s without triggering off muscle action potentials.

\subsection{Neuromuscular facilitation}

The muscle was bathed in Ringer solution with low $\mathrm{Ca}^{2+}$ and high $\mathrm{Mg}^{2+}$ and stimulated once every $5 \mathrm{sec}$ with a train of 5 pulses at $200 \mathrm{~Hz}$ followed by a single stimulus $40 \mathrm{msec}$ after the end of the train. 64 sweeps were automatically averaged before measurements of peak amplitudes of e.p.p.'s were taken. According to Rahamimoff and Colomo (1967) this gives a statistically reliable measure of the mean e.p.p. amplitude (S.D. $<5 \%$ ) 
when the quantal content $m \geqslant 10$, as was the case in most of our experiments. Whenever an e.p.p. was superimposed on the declining phase of a previous e.p.p. its amplitude was measured vertically from the peak of the e.p.p. to the projected tail of the previous one. Facilitation was defined according to Mallart and Martin (1967) as

$\mathrm{f}=\left(\mathrm{E}-\mathrm{E}_{0}\right) / \mathrm{E}_{0}$

where $E_{0}$ is the averaged amplitude of the initial e.p.p. and $E$ is the averaged amplitude of a test e.p.p. within the train. Only the early component of the cumulative neuromuscular facilitation as demonstrated by Mallart and Martin (1967) was studied in this investigation. The time constant of decay of facilitation was determined by using 10,20 and 30 msec intervals between a single conditioning stimulus and a test stimulus. Again, 64 sweeps were automatically averaged at a frequency of $2 \mathrm{~Hz}$.

\subsection{Neuromuscular depression}

Curarized preparations were stimulated with a train of 10 pulses at $50 \mathrm{~Hz}$ followed by a single test stimulus $0.9 \mathrm{sec}$ after the end of the train. Neuromuscular depression was expressed as $\left(E_{0}-E\right) / E_{0} \times 100 \%$, where $E_{0}$ is the amplitude of the first e.p.p. in the train and $E$ the amplitude of the test response (Otsuka et al., 1962). The mean \pm S.D. of 5 successive determinations of depression was calculated.

\section{Results}

\subsection{End-plate potential}

The effect of aldrin-transdiol $(2.5 \times$ $10^{-5} \mathrm{M}$ ) on the e.p.p. peak amplitude of junctions bathed in Ringer solution with low $\mathrm{Ca}^{2+}$ and high $\mathrm{Mg}^{2+}$ is illustrated in fig. 1. Upon application of aldrin-transdiol to the bathing fluid the e.p.p. amplitude began to increase markedly and it reached a maximum of about

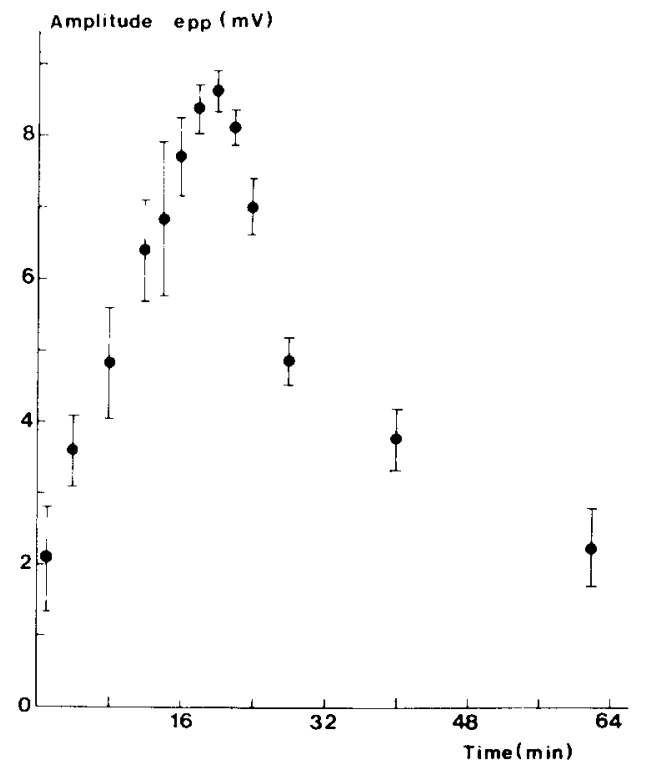

Fig. 1. Effect of aldrin-transdiol on end-plate potential amplitude in Ringer solution with low $\mathrm{Ca}^{2+}$ and high $\mathrm{Mg}^{2+} .2 .5 \times 10^{-5} \mathrm{M}$ aldrin-transdiol was added to the bath at time zero. Mean end-plate potential amplitudes \pm S.D. $(n=200)$ were plotted halfway through measuring periods lasting $2 \mathrm{~min}$.

4 times control value at $20 \mathrm{~min}$. After that the amplitude gradually declined and ultimately transmission was completely blocked (not shown in the figure). The average maximum increase in e.p.p. size in 10 junctions exposed to $2.5 \times 10^{-5} \mathrm{M}$ aldrin-transdiol was $3.5 \pm 0.6$ times control value (mean \pm S.D.). Time course of the single e.p.p. was not affected by aldrin-transdiol. These results corroborate our earlier observations (Akkermans et al., 1974).

Prolonged nerve stimulation at a relatively low frequency (e.g., $2 \mathrm{~Hz}$ for $10 \mathrm{~min}$ ) causes a progressive decline in e.p.p. size in normal or in curarized frog muscles because of transmitter depletion (Del Castillo and Katz, 1954b; Capek et al., 1971). Control experiments showed that stimulation frequencies of below $0.1 \mathrm{~Hz}$ did not significantly affect e.p.p. amplitude. This is illustrated by fig. 2 which shows that the e.p.p. amplitude remained constant for $1 \mathrm{hr}$ in a curarized junction stimulated at a frequency of $0.07 \mathrm{~Hz}$. The regres- 


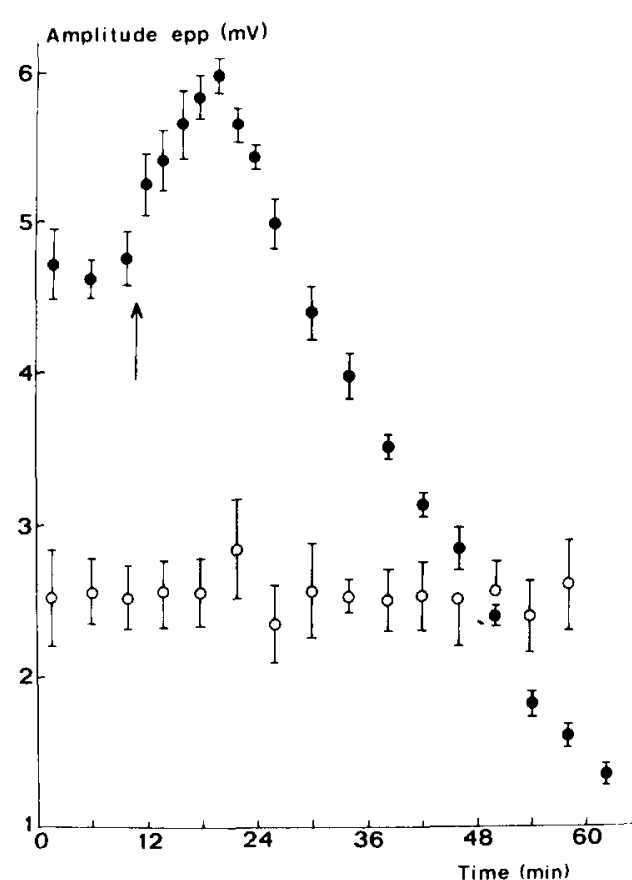

Fig. 2. End-plate potential amplitude in two curarized $\left(3 \times 10^{-6} \mathrm{~g} / \mathrm{ml}\right)$ junctions, in the control situation $(0)$ and after adding $2.5 \times 10^{-5} \mathrm{M}$ aldrin-transdiol to the perfusion fluid $(\bullet)$ as indicated by an arrow. Note the difference in end-plate potential amplitude before $\mathrm{t}=12 \mathrm{~min}$ (arrow) although the same d-tubocurarine chloride concentration was used. The mean end-plate potential amplitudes \pm S.D. were plotted in the middle of each measuring period of $2 \mathrm{~min}$. The motor nerve was stimulated at $0.07 \mathrm{~Hz}$.

sion was calculated to be linear (F-test, $p>$ $0.05)$ and the regression coefficient $(b=$ 0.0027 ) was insignificantly different from zero (Student's $t$-test, $p>0.1$ ). Fig. 2 also shows the effect of aldrin-transdiol on e.p.p. amplitude in a curarized junction. In this case aldrin-transdiol caused only a slight increase in e.p.p. size to a maximum of 1.26 times control value (significantly different from the control, Student's $t$-test, $p<0.001$ ) before the e.p.p. began to decrease. In three other experiments the maximal increase was even less; i.e., $1.18(p<0.001), 1.10(p<0.01)$ and $1.06(p<0.05)$ times control value. Four other curarized junctions showed no significant increase and the e.p.p. amplitude gradually decreased after application of aldrin- transdiol. It is worth noting that in several experiments the concentration of d-tubocurarine chloride in the bath had to be raised because the muscle started contracting after the application of aldrin-transdiol; indicating thereby that the e.p.p. in a number of fibres reached threshold. No clear correlation between the aldrin-transdiol-induced change in e.p.p. amplitude and the amount of curare was observed.

\subsection{Neuromuscular facilitation}

E.p.p.'s from junctions bathed in Ringer solution with low $\mathrm{Ca}^{2+}$ and high $\mathrm{Mg}^{2+}$ show a marked fluctuation in size as a result of low quantal content (Del Castillo and Katz, 1954a). For this reason measurements were taken on 64 automatically averaged recordings. Stimulation of the motor nerve with a train of stimuli results in a progressive increase in the amplitude of successive e.p.p.'s within the train (fig. 3A). This facilitation of e.p.p. is due to an increased transmitter release from the nerve terminal (Del Castillo and Katz, 1954b). The size of an e.p.p. evoked at $40 \mathrm{msec}$ after the end of the train is

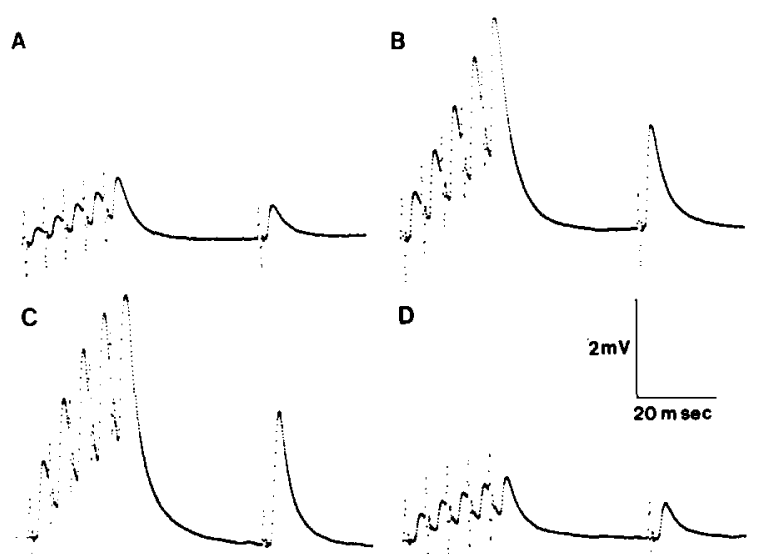

Fig. 3. The effect of aldrin-transdiol on neuromuscular facilitation. 64 sweeps were automatically averaged, before (A) and at 7.5 (B), 10 (C) and $20 \mathrm{~min}$ (D) after addition of $2.5 \times 10^{-5} \mathrm{M}$ aldrin-transdiol to the bath. Note the large and transient increase in end-plate potential amplitude after aldrin-transdiol. 
still increased in relation to the first e.p.p. of the train. Facilitation of transmitter release at paired or at train stimulation is a phenomenon which has been found in many synapses. Because this process is thought to reflect basic properties of the release mechanism, we used the facilitation process to analyse the observed effects of aldrin-transdiol on transmitter release. Figs. $3 \mathrm{~B}-\mathrm{D}$ are sample records from the same end-plate after treatment with $2.5 \times 10^{-5} \mathrm{M}$ aldrin-transdiol. Most striking in this figure is the marked increase in e.p.p. amplitude with time (figs. 3B,C) followed by a decrease (fig. 3D). Aldrin-transdiol, however, also affected cumulative facilitation within the train. This is more clearly illustrated by fig. 4. Facilitation calculated from
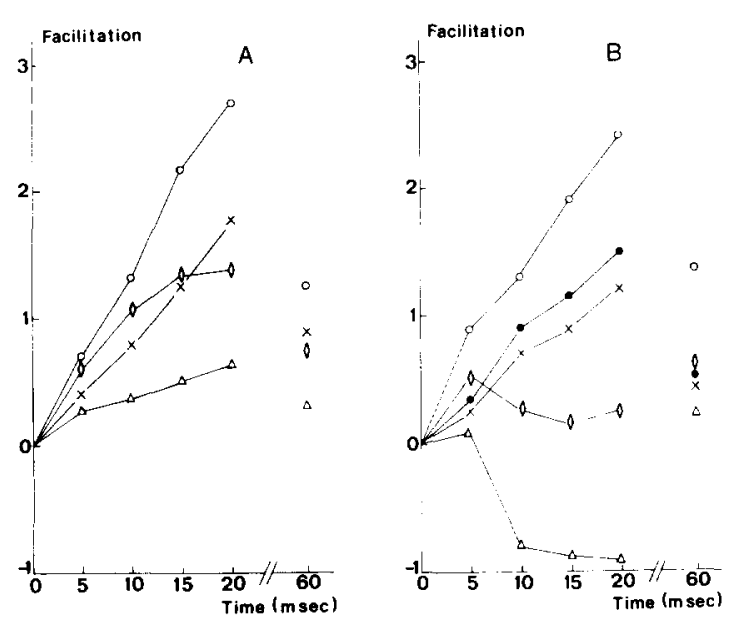

Fig. 4. The effect of aldrin-transdiol on neuromuscular facilitation. The facilitation in (A) was calculated from data of fig. 3 . Recordings were made before $(X)$ and at $7.5(0), 10(\diamond)$ and $20 \mathrm{~min}(\triangle)$ after addition of $2.5 \times 10^{-5}(\mathrm{~A})$ and $5 \times 10^{-5} \mathrm{M}(\mathrm{B})$ aldrin-transdiol to the perfusion fluid. Partial recovery of the effect of aldrin-transdiol is demonstrated in B (๑) after a wash-out period of about $40 \mathrm{~min}$ following a $20 \mathrm{~min}$ period of treatment. Symbols at $t=60 \mathrm{msec}$ indicate the facilitation of the end-plate potential at $40 \mathrm{msec}$ after the end of the train (cf. fig. 3). The cumulative facilitation in $(A O, \triangle)$ and $(B O, \diamond, \triangle)$ is significantly different from the control since the estimated $95 \%$ confidence interval of each of these cumulative facilitation curves does not overlap the $95 \%$ confidence intervals of the control curves. the data in fig. 3 is shown in fig. 4A. Fig. 4B shows the results of exposing a junction to 5 $\times 10^{-5} \mathrm{M}$ aldrin-transdiol. At first aldrintransdiol caused a significant increase in cumulative facilitation within the train, and the post-train e.p.p. was also augmented in size in relation to the initial e.p.p. This increase in facilitation was transient and after $20 \mathrm{~min}$ of exposure to $2.5 \times 10^{-5} \mathrm{M}$ aldrin-transdiol the growth of facilitation during the train and the facilitation of the post-train e.p.p. were considerably reduced. Treatment with $5 \times$ $10^{-5} \mathrm{M}$ aldrin-transdiol (fig. 4B) resulted in more pronounced effects and finally even a 'negative facilitation' was to be seen during the train while the facilitation of the posttrain e.p.p. was only slightly affected. The decline in facilitation after prolonged aldrintransdiol treatment is probably the result of an effect of aldrin-transdiol on neuromuscular depression, as will be described in paragraph 3.3. A significant increase in cumulative facilitation followed by a decrease was observed in 4 other experiments of this nature. In separate control experiments it was shown that the time course of the cumulative facilitation measured at 5, 10, 15 and 20 min after start of the experiment remained constant. Fig. $4 \mathrm{~A}, \mathrm{~B}$ also shows that during the phase of an augmented facilitation the post-train e.p.p. was affected by aldrin-transdiol to the same extent as the growth of facilitation during the train, indicating thereby that the decay of facilitation was not influenced by aldrin-transdiol. This was more accurately measured by stimulating the motor nerve with double pulses with varying intervals. In control junctions the decay in facilitation could be described approximately by a single exponential curve (Mallart and Martin, 1967) with a time constant of $30.3 \pm 3.2$ msec (mean \pm S.D., $n=5$ ). After treatment with $2.5 \times 10^{-5} \mathrm{M}$ aldrin-transdiol the time constant of decay of the augmented facilitation was $36.2 \pm 9.8$ (mean \pm S.D., $n=5$ ). The difference is not significant (Student's $t$-test, $p>0.8$ ).

The maximum increase in e.p.p. amplitude (fig. 3C, corresponding with fig. $4 \mathrm{~A}, \diamond$ ) does 
not coincide with the maximum facilitation (fig. 4A, O, corresponding with fig. 3B).

Fig. $4 \mathrm{~A}, \diamond$ clearly shows that at the time of maximum e.p.p. size the facilitation curve was already less steep and that the facilitation of the last two responses in the train was suppressed.

Fig. 4B, - shows that by washing the preparation with normal Ringer solution the aldrintransdiol effect could be reversed. After a wash-out period of about 40 min the suppressive effect of aldrin-transdiol disappeared and the facilitation was almost back to control level.

\subsection{Neuromuscular depression}

Depression of transmitter release after single or train stimulation is another synaptic property, which has been used for a further definition of the effects of aldrin-transdiol on transmitter release. The amplitude of an e.p.p. evoked at $0.9 \mathrm{sec}$ after the end of a conditioning train of 10 successive nerve impulses in a curarized junction was reduced to $44 \%$ of the amplitude of the initial e.p.p. of the train (fig. 5). This depression is due to a decrease in transmitter release from the nerve terminal (Otsuka et al., 1962; Thies, 1965).

In our control experiments the overall stimulation rate was chosen so as to keep the

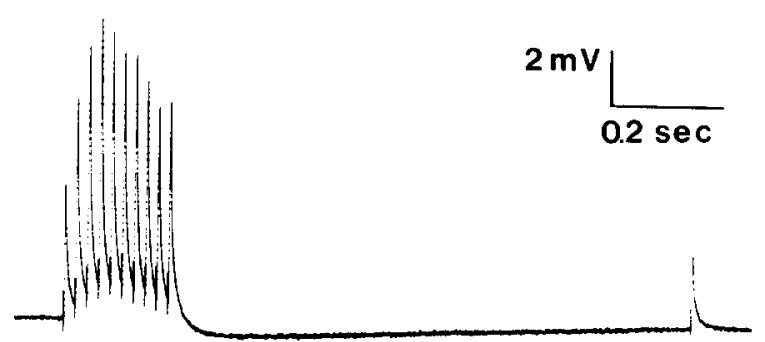

Fig. 5. Neuromuscular depression in a curarized $(2 \times$ $10^{-6} \mathrm{~g} / \mathrm{ml}$ ) junction. The motor nerve was stimulated with a conditioning train of 10 pulses followed by a single test pulse. The test response is depressed in relation to the initial end-plate potential (ac coupled recording). depression constant for more than $1 \mathrm{hr}$. A series of 5 conditioning-test sequences at 20 sec intervals every $8 \mathrm{~min}$ proved to be satisfactory, as illustrated by fig. $6 \mathrm{~A}$. The line in this figure is fitted by the method of least squares; the regression was calculated to be linear ( $F$ test, $p>0.05$ ) and the regression coefficient $(b=0.04)$ was insignificantly different from

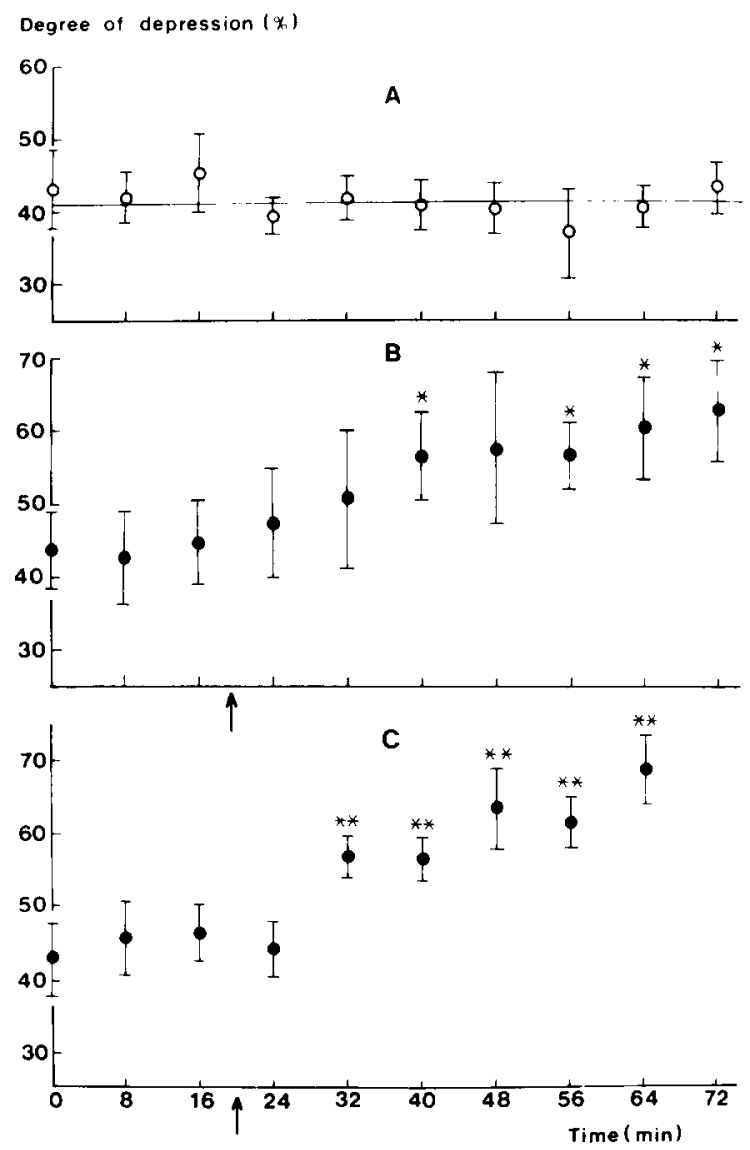

Fig. 6. Effect of aldrin-transdiol on neuromuscular depression in 2 curarized junctions. The motor nerve was stimulated every $8 \mathrm{~min}$ with a series of 5 conditioning-test sequences at $20 \mathrm{sec}$ intervals as illustrated in fig. 5. The mean depression \pm S.D. was plotted at the start of every period of $8 \mathrm{~min}$. In the control situation (A) the depression remained constant for more than $1 \mathrm{hr}$ (see text). After addition of aldrintransdiol (arrow) in a concentration of $10^{-5} \mathrm{M}$ (B) and $3 \times 10^{-5} \mathrm{M}(\mathrm{C})$ there was a significant enhancement of depression (Student's $t$-test: ${ }^{*} p<0.05, * * p$ $<0.002$ ). 
zero (Student's $t$-test, $p>0.05$ ). Fig. 6B shows that neuromuscular depression was significantly increased after $20 \mathrm{~min}$ of exposure to $10^{-5} \mathrm{M}$ aldrin-transdiol from $43 \pm 5$ to $56 \pm$ $6 \%$ and reached $62 \pm 7 \%$ after $50 \mathrm{~min}$ of exposure. Treatment with $3 \times 10^{-5} \mathrm{M}$ aldrintransdiol (fig. 6C) had a more pronounced effect and after $12 \mathrm{~min}$ of exposure the depression was significantly increased from $44 \pm$ 5 to $57 \pm 3 \%$ and after $44 \mathrm{~min}$ of exposure to $68 \pm 5 \%$. At later stages of the experiment most conditioning e.p.p.'s were completely blocked by aldrin-transdiol.

\section{Discussion}

In an earlier investigation we demonstrated (Akkermans et al., 1974) that the aldrin-transdiol-induced increase in e.p.p. amplitude in $\mathrm{Mg}^{2+}$-blocked preparations is of presynaptic origin and is due to an increase in quantal content. In the present study a significant increase in e.p.p. size was also observed in junctions where the process of transmitter release is not impaired, i.e., in curarized junctions. In this case, however, the increase in e.p.p. amplitude is much smaller than under conditions of low quantal content, and even absent at times. Since aldrin-transdiol has a postsynaptic blocking action as well (Akkermans et al., 1974) this might indicate that aldrin-transdiol and d-tubocurarine have a synergistic action on the postsynaptic membrane. However, no clear correlation could be established between the concentration of $d$ tubocurarine and the effect of aldrin-transdiol on e.p.p. amplitude. On the other hand it could be that at higher values of quantal content aldrin-transdiol causes earlier exhaustion of transmitter stores in the terminals; the more because aldrin-transdiol also increases spontaneous release (Akkermans et al., 1974).

The present study clearly demonstrates that aldrin-transdiol also causes a marked increase in neuromuscular facilitation during train stimulation. Katz and Miledi (1965, 1968,1970 ) have supplied much evidence to prove that the entry of external calcium ions into the nerve terminal is an essential step between depolarization of the membrane and release of transmitter. These authors have further argued that the build-up of facilitation during repetitive stimulation within a train can be accounted for by accumulation of residual calcium ions remaining in the terminal after each nerve impulse. In terms of this 'calcium hypothesis' there are at least two mechanisms which would lead to an increase in neuromuscular facilitation. Firstly, the amount of calcium entering the nerve terminal during an action potential may be increased or, secondly, the removal of 'active calcium' after each nerve impulse is inhibited. However the decay of facilitation was found not to be seriously affected by aldrin-transdiol even when the build-up of facilitation was markedly augmented. This suggests that the removal of calcium from the active sites on the inner surface of the axon membrane is not impaired. The simplest explanation would then be that aldrin-transdiol causes an increase in the amount of calcium which enters the axon terminal during the nerve impulse. This effect of aldrin-transdiol could explain both the increase in quantal content and the increase in facilitation. It should be noted, however, that only an increased influx of calcium during a nerve impulse would lead to increased quantal content coinciding with augmented facilitation, while an accumulation of intracellular calcium as caused by high external calcium (Rahamimoff, 1968) or by cardiac glycosides (Hubbard and Quastel, 1973) would lead to an increase in quantal content without increasing facilitation. On the other hand we have previously demonstrated (Akkermans et al., 1974) that aldrin-transdiol induces a marked increase in spontaneous transmitter release, which is largely independent of the presence of external calcium. This might indicate that aldrin-transdiol could affect a step in the release process in which calcium is probably not essential as does ethanol (Quastel et al., 1971).

The aldrin-transdiol-induced increase in 
e.p.p. amplitude and in neuromuscular facilitation was transient. After prolonged treatment with aldrin-transdiol both e.p.p. amplitude and facilitation began to decrease and in the end transmission was almost completely abolished. In our earlier work (Akkermans et al., 1974) we demonstrated by iontophoretic application of acetylcholine that aldrin-transdiol reduces the chemical sensitivity of the post-junctional membrane. In addition, however, we observed a progressive decrease in quantal content and a suppressive effect of aldrin-transdiol on the increase in spontaneous transmitter release brought about by a high external potassium ion concentration. This suggests that aldrin-transdiol also has a presynaptic blocking effect (Akkermans et al., 1974). This latter effect is further substantiated by the finding in the present study that aldrin-transdiol enhanced neuromuscular depression. Neuromuscular depression is caused by a gradual decrease of transmitter release per nerve impulse as a result of partial depletion of available transmitter (Otsuka et al., 1962; Thies, 1965). According to Otsuka and Endo (1960), Otsuka and Nonomura (1962) and Thies (1965) the increase in transmitter release by a drug would always lead to an enhancement of neuromuscular depression if the available transmitter store remained unchanged or decreased. Thus the enhancement of depression observed in the present experiments might be solely due to the previously augmented transmitter release. Such a depletion of transmitter as a result of previous excessive release has actually been suggested by Shankland and Schroeder (1973) to account for the blocking effect of dieldrin, or one of its metabolites, in the sixth abdominal ganglion of the cockroach. Partial depletion of the available store as a consequence of an increased transmitter release has also been proposed by Gage (1965) to explain the neuromuscular depression caused by ethanol. In the present study, however, a marked inhibition of transmitter release already occurred under conditions of low quantal content, resulting in a decrease of facilitation and, final- ly, even in a 'negative facilitation' (see fig. 4B). A direct effect of aldrin-transdiol on transmitter mobilization (Elmqvist and Quastel, 1965) is probably the main cause which limited the amount of available acetylcholine and restricted the amount of acetylcholine per nerve impulse. Furthermore the small decremental effect of aldrin-transdiol on the post-train facilitation after prolonged treatment as compared with the marked inhibition of facilitation during the train (fig. 4B) suggests that the availability of transmitter during repetitive stimulation was impaired and that at 40 msec after the end of the train the available store was partially refilled. It would appear therefore that, apart from an increase in spontaneous and evoked transmitter release and a post-synaptic blocking action, aldrintransdiol also has a direct inhibitory effect on the availability of transmitter.

Van den Bercken and Narahashi (1974) have recently reported a suppressive effect of aldrin-transdiol on the action potential and on ionic conductances in squid giant axons. Such a suppression of the nerve action potential will also contribute to the blocking effect of aldrin-transdiol on synaptic transmission as we discussed in our previous paper (Akkermans et al., 1974).

The insecticide dieldrin has long been known to affect skeletal muscular contraction. Khaïry (1960) reported that rats chronically treated with dieldrin showed a quick development of fatigue after muscular exercise. Ibrahim (1964) and van Genderen and Ibrahim (1965) also observed that one of the actions of dieldrin is a rapid loss of force during a tetanic contraction evoked through the nerve. Both phenomena could be due to an enhancement in neuromuscular depression leading to an increased failing of neuromuscular action potential transmission (increased Wedensky inhibition). The results of the present investigation cannot provide a conclusive explanation for the proposed effects of dieldrin on muscular contraction by direct stimulation (Ibrahim, 1964; Van den Bercken et al., 1973). It seems obvious that effects of 
aldrin-transdiol on synaptic transmission in the spinal cord and in the central nervous system similar to those described here for the neuromuscular junction, would be more relevant for the understanding of the mechanism of dieldrin- and aldrin-poisoning (Gowdey et al., 1952, 1954, 1955; Natoff and Reiff, 1967; Narahashi, 1971). The effects of dieldrin and aldrin-transdiol on synaptic transmission in the isolated spinal cord of the frog will be described in a following paper.

\section{Acknowledgements}

The authors wish to thank Prof. H. van Genderen for his interest in this study and Mr. D.L. IJpeij for helpful criticisms on the manuscript. We are indebted to Shell Research Ltd, Tunstall Laboratory, Kent for the gift of aldrin-transdiol. This work was sponsored by the Foundation for Medical Research, FUNGO, and by the Shell Corporation.

\section{References}

Akkermans, L.M.A., J.M. Van der Zalm and J. Van den Bercken, 1973, Is aldrin-transdiol the active form of the insecticide dieldrin? Arch. Intern. Pharmacodyn. 206, 363.

Akkermans, L.M.A., J. Van den Bercken, J.M. Van der Zalm and H.W.M. Van Straaten, 1974, Effects of dieldrin (HEOD) and some of its metabolites on synaptic transmission in the frog motor end-plate, Pestic. Biochem. Physiol. 4, 313.

Baldwin, M.K., J. Robinson and D.V. Parke, 1972, A comparison of the metabolism of HEOD (dieldrin) in the CF1 mouse with that in the CFE rat, Fd Cosmet. Toxicol. 10, 333.

Bann, J.M., T.J. DeCino, N.W. Earle and Y.P. Sun, 1965, The fate of aldrin and dieldrin in the animal body, J. Agr. Food Chem. 4, 937.

Brooks, G.T., 1960, Mechanisms of resistance of the adult housefly (Musca domestica) to 'cyclodiene' insecticides, Nature 186, 96.

Čapek, R., D.W. Esplin and S. Salehmoghaddam, 1971 , Rates of transmitter turnover at the frog neuromuscular junction estimated by electrophysiological techniques, J. Neurophysiol. 34, 831.

DelCastillo, J, and B. Katz, 1954a, Quantal components of the end-plate potential, J. Physiol. 124, 560 .
Del Castillo, J. and B. Katz, 1954b, Statistical factors involved in neuromuscular facilitation and depression, J. Physiol. 124, 574.

Elmqvist, D. and D.M.J. Quastel, 1965, A quantitative study of endplate potentials in isolated human muscle, J. Physiol. 178, 505.

Feil, V.J., R.D. Hedde, R.G. Zaylskie and C.H. Zachrison, 1970, Identification of trans-6,7-dihydroxydihydroaldrin and 9-(syn-epoxy) hydroxy $-1,2,3,4$, 10,10 -hexachloro - 6,7 -epoxy - $1,4,4 \mathrm{a}, 5,6,7,8,8 \mathrm{a}$-octahydro-1,4-endo-5,8-exo-dimethanonaphthalene, J. Agr. Food Chem. 18, 120.

Gage, P.W., 1965, The effect of methyl, ethyl and $n$-propyl alcohol on neuromuscular transmission in the rat, J. Pharmacol. Exptl. Therap. 150, 236.

Genderen, H. van, and T.M. Ibrahim, 1965, The action of dieldrin on striated muscles of the rat, Acta Physiol. Pharmacol. Neerl. 13, 193.

Giannotti, O., R.L. Metcalf and R.B. March, 1956, The mode of action of aldrin and dieldrin in Periplaneta americana (L.), Ann. Entomol. Soc. Amer. $49,588$.

Gowdey, C.W., A.R. Graham, J.J. Seguin, G.W. Stavraky and $\mathrm{R}$.A. Waud, 1952, A study of the pharmacological properties of the insecticide aldrin, Can. J. Med. Sci. 30, 520.

Gowdey, C.W., A.R. Graham, J.J. Seguin and G.W. Stavraky, 1954, The pharmacological properties of the insecticide dieldrin, Can. J. Biochem. Physiol. 32,498 .

Gowdey, C.W. and G.W. Stavraky, 1955, A study of the autonomic manifestation seen in acute aldrin and dieldrin poisoning, Can. J. Biochem. Physiol. $33,272$.

Hubbard, J.I. and D.M.J. Quastel, 1973, Micropharmacology of vertebrate neuromuscular transmission, Ann. Rev. Pharmacol. 13, 199.

Ibrahim, T.M., 1964, A toxicological study of the action of the insecticide dieldrin and related substances on the contraction of striated muscle in the rat, Thesis, University of Utrecht, The Netherlands.

Katz, B. and R. Miledi, 1965, The effect of calcium on acetylcholine release from motor nerve terminals, Proc. Roy. Soc. B 161, 496.

Katz, B. and R. Miledi, 1968, The role of calcium in neuromuscular facilitation, J. Physiol. 195, 481.

Katz, B. and R. Miledi, 1970, Further study of the role of calcium in synaptic transmission, J. Physiol. 207,789 .

Khaïy, M., 1960, Effects of chronic dieldrin ingestion on the muscular efficiency of rats, Brit. J. Industr. Med. 17, 146.

Korte, F. and H. Arent, 1965, Metabolism of insecticides, IX (1) Isolation and identification of dieldrin metabolites from urine of rabbits after oral administration of dieldrin-14 C, Life Sci. 4, 2017. 
Mallart, A. and A.R. Martin, 1967, An analysis of facilitation of transmitter release at the neuromuscular junction of the frog, J. Physiol. 193, 679.

Matsumura, F., 1972, Metabolism of insecticides in microorganisms and insects, in: Environmental Quality and Safety, Vol. 1, eds. F. Coulston and F. Korte (George Thieme Verlag, Stuttgart and Academic Press, New York) p. 96.

Matthews, H.B. and F. Matsumura, 1969, Metabolic fate of dieldrin in the rat, J. Agr. Food Chem. 17, 845.

Narahashi, T, 1971, Effects of insecticides on excitable tissues, in: Advances in Insect Physiology, Vol. 8, eds. J.W.L. Beament, J.E. Treherne and V.B. Wigglesworth (Academic Press, London and New York) p. 1.

Natoff, I.L. and B. Reiff, 1967, The effects of dieldrin (HEOD) on chronaxie and convulsion thresholds in rats and mice, Brit. J. Pharmacol. Chemotherap. 31, 197.

Otsuka, M. and M. Endo, 1960, The effect of guanidine on neuromuscular transmission, J. Pharmacol. Exptl. Therap. 128, 273.

Otsuka, M., M. Endo and Y. Nonomura, 1962, Presynaptic nature of neuromuscular depression, Jap. J. Physiol. 12, 573.

Otsuka, M. and Y. Nonomura, 1962, The action of phenolic substances on motor nerve endings, J. Pharmacol. Exptl. Therap. 140, 41.

Quastel, D.M.J., J.T. Hackett and J.D. Cooke, 1971, Calcium: Is it required for transmitter secretion? Science 172, 1034.

Rahamimoff, R., 1968, A dual effect of calcium ions on neuromuscular facilitation, J. Physiol. 195, 471 .
Rahamimoff, R. and F. Colomo, 1967, Inhibitory action of sodium ions on transmitter release at the motor end-plate, Nature 215, 1174.

Ryan, W.H. and D.L. Shankland, 1971, Synergistic action of cyclodiene insecticides with DDT on the membrane of giant axons of the American cockroach Periplaneta americana (L.), Life Sci. 10, Part I, 193 .

Shankland, D.L. and M.E. Schroeder, 1973, Pharmacological evidence for a discrete neurotoxic action of dieldrin (HEOD) in the American cockroach, Periplaneta americana (L.), Pestic. Biochem. Physiol. 3, 77.

Thies, R.E., 1965, Neuromuscular depression and the apparent depletion of transmitter in mammalian muscle, J. Neurophysiol. 28, 427.

Tomlin, A.D., 1968, trans-Aldrin glycol as a metabolite of dieldrin in larvae of the southern house mosquito, J. Econ. Entomol. 61, 855.

Van den Bercken, J., 1972, The effect of DDT and dieldrin on myelinated nerve fibres, European J. Pharmacol. 20, 205.

Van den Bercken, J., L.M.A. Akkermans and R.G. van Langen, 1973, The effect of DDT and dieldrin on skeletal muscle fibres, European J. Pharmacol. 21,89 .

Van den Bercken, J. and T. Narahashi, 1974, Effects of aldrin-transdiol, a metabolite of the insecticide dieldrin, on nerve membrane, European J. Pharmacol. 27,255 .

Wang, C.M., T. Narahashi and M. Yamada, 1971, The neurotoxic action of dieldrin and its derivatives in the cockroach, Pestic. Biochem. Physiol. 1, 84. 